\title{
İstilacı Bir Tür Atherina boyeri Risso, 1810'nin Eğirdir Gölü Popülasyonunda Morfometrik ve Bazı Kemiksi Yapıların Biyometrik Özellikleri
}

\section{Derya BOSTANCI ${ }^{*}$ Meral APAYDIN YAĞCI ${ }^{2}$ Seda KONTAŞ ${ }^{3}$ Gülşah KURUCU ${ }^{1}$ Nazmi POLAT ${ }^{4}$}

${ }^{1}$ Ordu Üniversitesi, Fen Edebiyat Fakültesi, Biyoloji Bölümü- Ordu

${ }^{2} \mathrm{Su}$ Ürünleri Araştırma İstasyonu Müdürlüğü, Eğirdir- Isparta

${ }^{3}$ Ordu Üniversitesi, Fatsa Deniz Bilimleri Fakültesi, Balıkçılık Teknolojisi Müh. Bölümü- Ordu

${ }^{4}$ Ondokuz Mayıs Üniversitesi, Fen Edebiyat Fakültesi, Biyoloji Bölümü- Samsun

*Sorumlu yazar: deryabostanci@gmail.com

\section{Özet}

Bu çalışmada, Gümüş balığı Atherina boyeri Risso, 1810'nin morfometrik özellikleri ve bazı kemiksi yapılarının biyometrik özellikleri incelenmiştir. Toplam 182 örnek Ekim 2010 tarihinde Eğirdir Gölü’nden yakalanmıştır. Örneklerin ağırlıkları ve her biri üzerinde alınan 23 metrik uzunluğu, elektronik kumpas yardımıyla ölçülmüş ve kataloglara kaydedilmiştir. Örneklerin tam boyları 58,98-95,00 mm, ağırlıkları ise 1,35-5,39 g arasında dağılım göstermektedir. Değerlendirmeler sonucunda en değişken özellik ağırlık, en az değiş̧kenlik ise prepektoral mesafede tespit edilmiştir. Türün osteolojik özelliklerinden maksil, premaksil, operkül, preoperkül kemiklerinin sağ ve sol çiftlerinin biyometrik özellikleri farklı eksenler üzerinde belirlenmiş tablo ve şekillerle sunulmuştur.

Anahtar kelimeler: Gümüş balığı, Atherina boyeri, Eğirdir Gölü, morfometri, biyometri

Morphometric and Biometric Characteristics of Some Bony Structures of an Invasive Species Atherina boyeri in Eğirdir Lake Population

\begin{abstract}
Morphometric characteristics and some bony structure of the biometric characteristics of big-scale sand smelt Atherina boyeri Risso, 1810 were examined in this study. A total of 182 samples were caught from Eğirdir Lake in October 2010. The weight of the examples and the length taken from each example as 23 metric length was measured by electronic calipers and were recorded in catalogs. Total length and weight of the all specimens between $58.98-95.00 \mathrm{~mm}$ and $1.35-5.39 \mathrm{~g}$, respectively. As a result of the evaluations, while the most variable characteristic is weight, the least variety is detected in a prepectoral distance. The osteological properties which are the biometric characteristics of right and left pairs of maxillary, premaxillary, opercle, preoperculum of the species, were presented in tables and figures determined on different axes.
\end{abstract}

Key words: Big-scale send smelt, Atherina boyeri, Eğirdir Lake, morphometry, biometry

\section{GİRIŞ}

Tuzluluğa karşı geniş bir hoşgörüsü olan gümüş balıklarının (Geldiay ve Balık, 2009) dağılımı ile ilgili çeşitli kayıtlar 2001 yılında Hirfanlı ve Kapulukaya Baraj Göllerinden (Kuru vd., 2001), İznik Gölü’nden (Özeren, 2004), Eğirdir Gölü’nden (Yeğen vd., 2005) yapılmış ve ilgili göllerin bağlı olduğu sucul ekosistemlere de doğal yollardan ve insan etkisiyle taşınabileceği belirtilmiştir (Küçük vd., 2006). Polat ve Uğurlu (2007) Bafra Balık Gölü ve Karaboğaz Lagün'ünde de varlığını kaydetmiştir. Gediz Nehri havzasında, Marmara Gölü (Salihli-Manisa)'ndeki varlığı da 2013 yılında kayıtlara geçmiştir (İlhan ve Sarı, 2013). Ekmekçi (2013) gümüş balığının istila potansiyelini belirlemek üzere yaptıkları çalışmada; yurdumuzda ilk olarak 1940'ların ortalarında Sapanca Gölü’nde 
rastlandığını, 1991 yılında ise denizle doğrudan bağlantısı olmayan İznik Gölü’nde bulunduğunu belirterek istilacı bir özellikte olan gümüş balığının günümüzde yurdumuz iç suları için risk oluşturabileceğini ifade etmiştir.

Morfometrik karakterler, meristik karakterlerde olduğu gibi sadece embriyonik dönemde değil, tüm yaşam boyunca çevresel faktörlerin etkisi altında olduklarından, belirli bir süre sonra farklı bölgelerde yaşamlarını sürdüren balık toplulukları arasında fenotipik farklılıklar istatistiki anlamda geçerli olabilmektedir. Bu nedenle, hem meristik hem de morfometrik karakterler stok ayırma çalışmalarında kullanılmaktadır (Avşar, 1998).

Tüm popülasyonlar için standart ölçümlerin kullanılması popülasyonların karşılaştırılmasında daha gerçek sonuçları yansıtması açısından önemlidir. Bu nedenle, çeşitli çevrelerde yayılış gösteren türlerin boy-boy ilişkilerinin bilinmesiyle de balık türlerinin kondisyonu, üremesi ve yaşam evreleri hakkında birçok bilgiye ulaşılabilinmektedir. Bununla birlikte hem yerel hem de bölgesel tür ve popülasyonların morfolojik karşılaştırılmasına da olanak sağlanmaktadır (Taşkavak vd., 2012). Taşkavak vd. (2012)' nin, araştırmalarında İzmir Körfezi'nde yayılış gösteren gümüş balığ1 (Atherina boyeri)'nın bazı biyometrik özelliklerinden baş boyu/tam boy ve göz çapı/baş boyu ortalama oranları bakımından Ege kıyılarında daha büyük bireylerin olduğunu saptamışlardır. Küçük vd. (2006) gümüş balığının Eğirdir Gölü’ne girmesiyle birlikte göl ekosistemine ve balıkçılığa yapmış olduğu etkileri değerlendikleri çalışmada, türün bazı kemiksi yapılarını da incelemişlerdir.

Bu çalışmanın amacı ise hem iç sularda hem de denizlerde yaşayabilen gümüş balığı $A$. boyeri’nin Eğirdir Gölü popülasyonu için taksonomik ayrımlarında kullanılan bazı kemiksi yapılarının biyometrik özelliklerini, türün bazı morfometrik karakterleri ve bunların balık boyu ile olan ilişkilerini analiz etmektir.

\section{MATERYAL VE METOT}

Çalışmanın araştırma materyalini oluşturan toplam 182 Atherina boyeri Risso, 1810 örneği, Ekim 2010 tarihinde Eğirdir Gölü'nden yakalanmış ve balıkçılardan temin edilmiştir. Her bir balık örneği kurulandıktan ve varsa üzerindeki yabancı maddelerden temizlendikten sonra $\pm 0,2 \mathrm{~g}$ hassasiyetle elektronik terazi yardımıyla tartılarak ağırlıkları kaydedilmiştir. Örneklerin metrik ölçümleri, elektronik kumpas yardımıyla ölçülmüş ve kataloglara kaydedilmiştir. Tüm ölçümler $\pm 1 \mathrm{~mm}$ hassasiyetle yapılmıştır. Kataloglarda balığın yakalandığ 1 yer, tarih ve cinsiyetleri belirtilmiştir. Alınan metrik ölçümler Tablo 1'de verilmiş, Şekil 1'de balık üzerinde gösterilmiştir.

Tablo 1. Metrik ölçümler listesi
1. Standart Boy (SB)
2. Çatal Boy (ÇB)
3. Tam Boy (TB)
4. Preorbital Mesafe (PO)
5. Göz Çapı (GÇ)
6. Interorbital Mesafe (İO)
7. Baş Boyu (BB)
8. Baş Genişliği (BG)
9. Solungaç Kapağ $\breve{1}_{1}$ zunluğu (SKU)
10. Burun ucu 1.D.Y.Aras1 Mesafe $\left(\mathrm{BD}_{1}\right)$
11. Burun ucu 2.D.Y.Aras1 Mesafe $\left(\mathrm{BD}_{2}\right)$
12. Preanal Mesafe (PA)
13. Prepektoral Mesafe (PP)
14. Preventral Mesafe (PV)
15. 1.Dorsal Y. Taban Uzunluğu $\left(\mathrm{D}_{1} \mathrm{~T}\right)$
16. 2.Dorsal Y. Taban Uzunluğu $\left(\mathrm{D}_{2} \mathrm{~T}\right)$
17. Anal Y. Taban Uzunluğu (AT)
18. Pektoral Y. Taban Uzunluğu (PT)
19. Ventral Y. Taban Uzunluğu (VT)
20. Maksimum Vücut Yüksekliği (MxVY)
21. Kaudal Pedünkül Yüksekliği (KY)
22. Vücut Genişliği (VG)
23. Kaudal Pedünkül Genişliği (KG)
24. Ağırlık (W) 


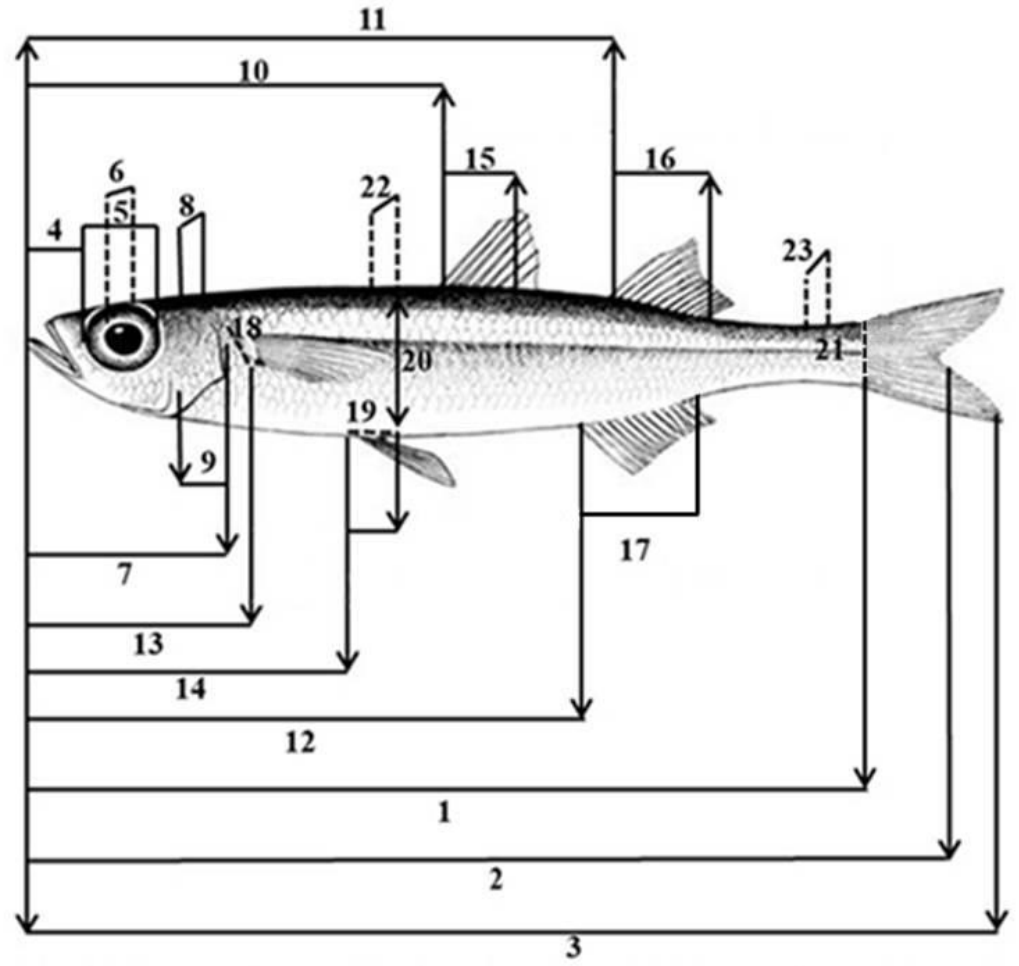

Şekil 1. Gümüş balığında alınan metrik ölçümler

Herhangi bir deformasyonu olmayan ve metrik ölçümleri yapılan bireyler dikkate alınarak vücut kısımları ve ağırlık ölçümlerinin tanımlayıcı istatistik bulguları olan ortalama, standart sapma, standart hata, minimum ve maksimum değerleri ile varyans katsayısı MINITAB 16.0 istatistik programı ile değerlendirilmiştir. Standart, çatal ve total boy değerleri ölçülen ortalama değerler olarak alınırken, diğer morfometrik özellikler standart boyun yüzdesi olarak verilmiştir. Ayrıca, varyans katsayısı değeri; $\% \mathrm{VK}=($ S.S./Ort.)*100 formülü kullanılarak hesaplanmıştır (Avşar, 1998) (Tablo 2). Çalışmada değerlendirilen ve vücut ölçümleri alınan A. boyeri bireylerinin sistematik incelemelerinde önemli olan metrik uzunlukları ile standart boyları arasındaki ilişkiler hesaplanmıştır.

Balık boyu ve ağırlığı arasındaki ilişki fonksiyoneldir. Bunun anlamı, balığın ağırlığındaki artışın boyun bir kuvveti şeklinde ifade edilmesidir. Tam boy ve ağırlık arasındaki ilişki;

$\mathrm{W}=\mathrm{aL}^{\mathrm{b}}$ eşitliğinden yararlanılarak hesaplanmıştır (Ricker, 1975). Burada;

$\mathrm{W}$ : Balık ağırlı̆̆ $(\mathrm{g})$

$\mathrm{L}:$ Tam boy $(\mathrm{cm})$

a ve b katsayıları göstermektedir.

Gümüş balığı Atherinidae familyası üyesidir ve premaksil kemiği bu familya için önemli taksonomik bir özelliktir (Küçük vd., 2006). Bu kemiğin yanında maksil, operkül, preoperkül kemikleri çiftler halinde çıkarılarak temizlenmiş, kurulanmış ve analizlerden 
önce uygun şekilde saklanmıştır. Maksil, premaksil, operkül, preoperkül kemikleri üzerlerindeki doku parçalarının ayrılması için kaynatılarak temizlenmiştir. Morfolojik ölçümler, stereo mikroskopa bağlı görüntüleme sistemi kullanılarak her kemiğin fotoğrafı çekilerek yapılmış eksen ölçümleri alınmıştır. Premaksil, maksil, operkül ve preoperkül kemiklerinin boyutlarını ölçmek için kemikler üzerinde eksenler belirlenmiş ve ölçümler alınmıştır. Alınan bu ölçümler Şekil 2-5'te gösterilmiştir.

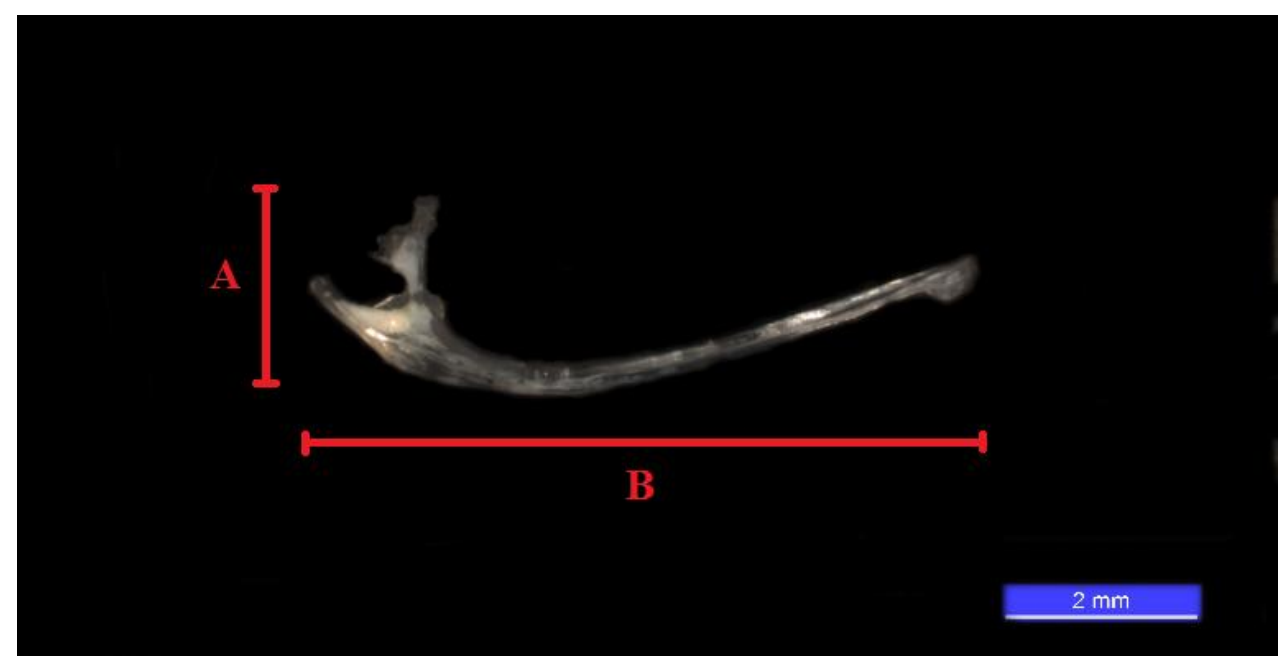

Şekil 2. Gümüş balığında maksil üzerinde ölçümü alınan eksenler

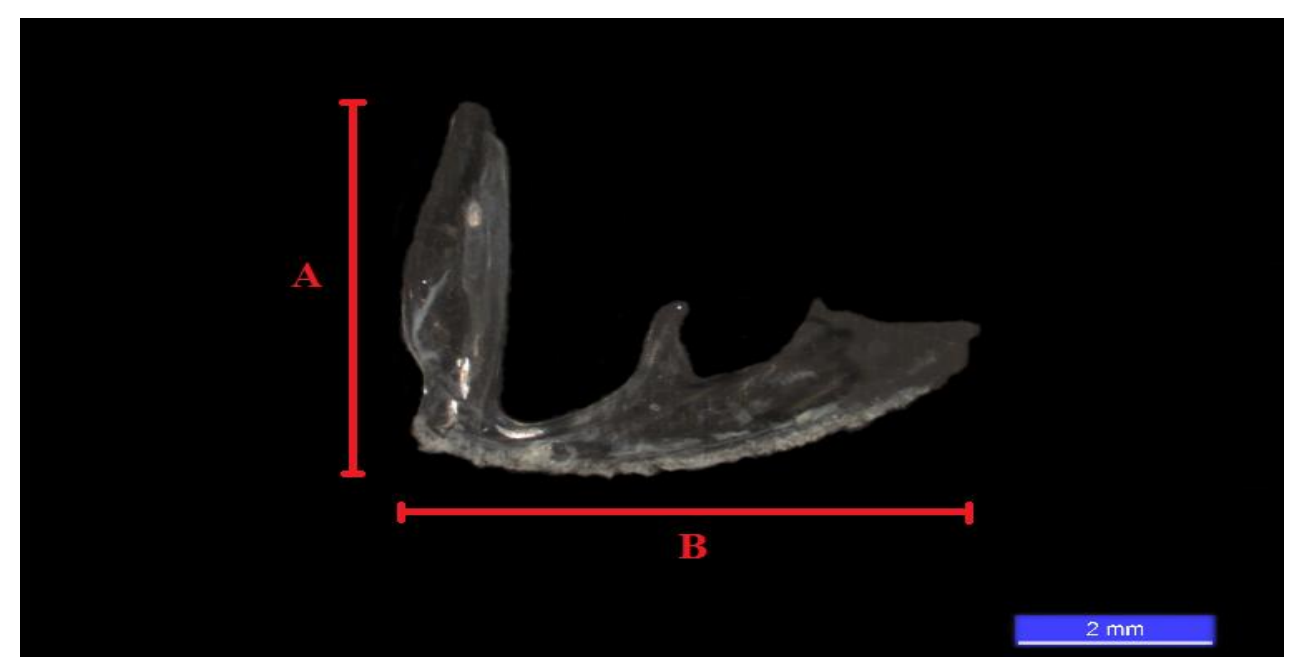

Şekil 3. Gümüş balığında premaksil üzerinde ölçümü alınan eksenler 


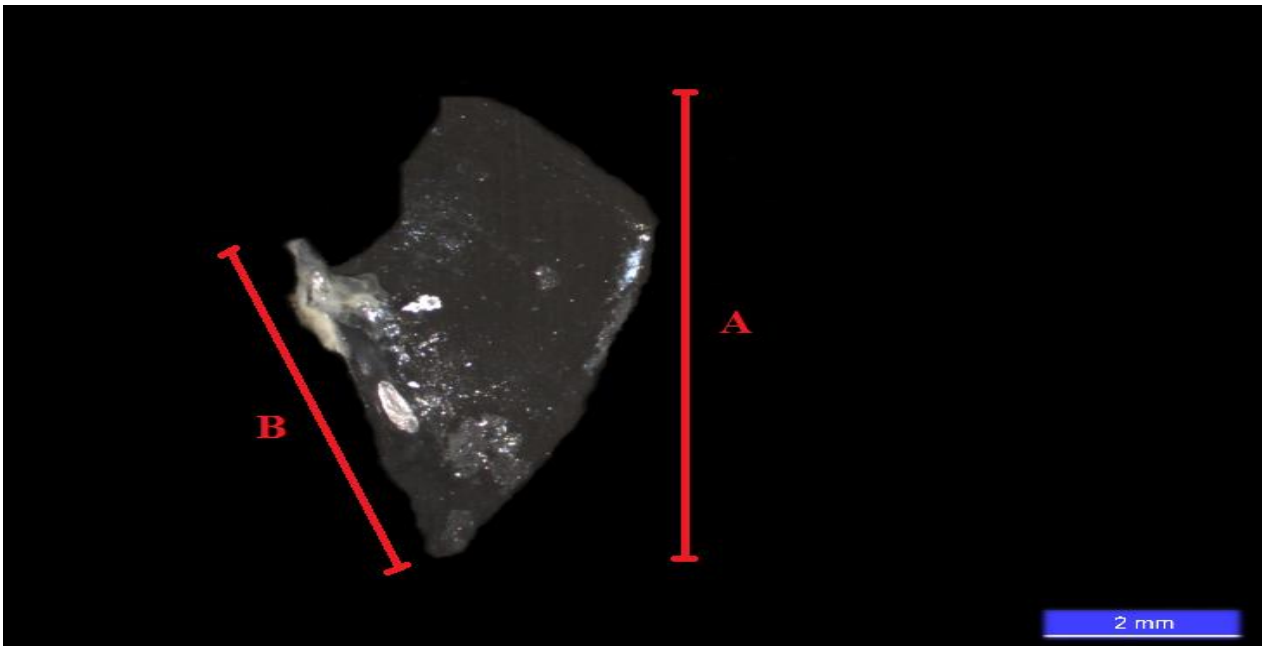

Şekil 4. Gümüş balığında operkül üzerinde ölçümü alınan eksenler

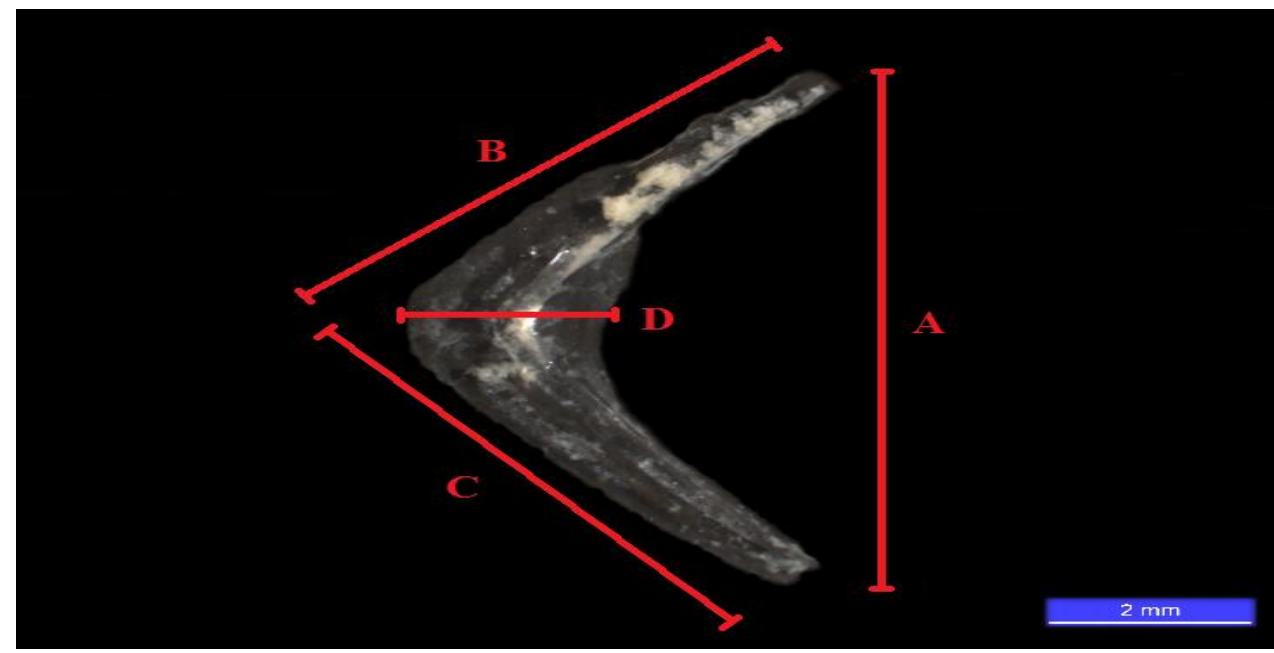

Şekil 5. Gümüş balığında preoperkül üzerinde ölçümü alınan eksenler

\section{BULGULAR}

Morfometrik değerlendirmelerde 182 balık örneğindeki ağırlık, standart, çatal ve tam boyun orijinal hali alınmış ve diğer karakterler ise standart boyun yüzdesi olarak Tablo 2'de verilmiştir. Bulunan değerlere göre, en değişken özellik ağırlık, en az değişkenlik ise prepektoral mesafede tespit edilmiştir. 
Tablo 2. Gümüş balığında metrik ölçümlere ait değerler

\begin{tabular}{|c|c|c|c|c|c|c|}
\hline Karakterler & Ort. & S.H. & S.S. & Min. & Maks. & \% VK \\
\hline SB & 68,79 & 0,354 & 4,766 & 54,13 & 82,66 & 9,65 \\
\hline ÇB & 74,63 & 0,381 & 5,144 & 58,69 & 89,08 & 6,89 \\
\hline TB & 79,55 & 0,408 & 5,505 & 58,98 & 95,00 & 6,92 \\
\hline $\mathrm{PO}(\% \mathrm{SB})$ & 6,48 & 0,033 & 0,449 & 5,13 & 7,67 & 9,33 \\
\hline $\mathrm{GÇ}(\% \mathrm{SB})$ & 8,03 & 0,036 & 0,478 & 6,60 & 9,06 & 6,74 \\
\hline İO $(\% \mathrm{SB})$ & 5,10 & 0,027 & 0,358 & 4,26 & 5,93 & 9,77 \\
\hline $\mathrm{BB}(\% \mathrm{SB})$ & 23,41 & 0,070 & 0,948 & 20,09 & 28,85 & 6,67 \\
\hline $\mathrm{BG}(\% \mathrm{SB})$ & 9,99 & 0,040 & 0,542 & 6,06 & 11,13 & 8,08 \\
\hline SKU (\%SB) & 6,85 & 0,035 & 0,471 & 5,49 & 8,71 & 8,56 \\
\hline $\mathrm{BD}_{1}(\% \mathrm{SB})$ & 43,79 & 0,319 & 4,295 & 5,16 & 47,67 & 11,88 \\
\hline $\mathrm{BD}_{2}(\% \mathrm{SB})$ & 66,30 & 0,108 & 1,457 & 62,84 & 71,22 & 7,21 \\
\hline $\mathrm{PA}(\% \mathrm{SB})$ & 63,96 & 0,099 & 1,340 & 59,79 & 67,09 & 7,16 \\
\hline $\mathrm{PP}(\% \mathrm{SB})$ & 25,46 & 0,073 & 0,980 & 23,23 & 27,79 & 6,62 \\
\hline PV (\%SB) & 38,53 & 0,121 & 1,567 & 33,16 & 42,30 & 7,65 \\
\hline $\mathrm{D}_{1} \mathrm{~T}(\% \mathrm{SB})$ & 7,85 & 0,058 & 0,777 & 5,65 & 9,86 & 12,59 \\
\hline $\mathrm{D}_{2} \mathrm{~T}(\% \mathrm{SB})$ & 12,62 & 0,082 & 1,107 & 3,12 & 15,21 & 10,59 \\
\hline $\mathrm{AT}(\% \mathrm{SB})$ & 15,92 & 0,085 & 1,144 & 12,89 & 19,10 & 9,52 \\
\hline $\mathrm{PT}(\% \mathrm{SB})$ & 4,87 & 0,216 & 2,912 & 3,72 & 43,54 & 9,51 \\
\hline VT (\%SB) & 2,11 & 0,019 & 0,251 & 1,61 & 2,80 & 13,49 \\
\hline $\operatorname{MxVY}(\% \mathrm{SB})$ & 14,18 & 0,113 & 1,518 & 8,96 & 27,01 & 14,43 \\
\hline $\mathrm{KY}(\% \mathrm{SB})$ & 4,72 & 0,024 & 0,328 & 3,67 & 5,56 & 9,02 \\
\hline $\mathrm{VG}(\% \mathrm{SB})$ & 8,37 & 0,061 & 0,821 & 6,08 & 10,51 & 13,08 \\
\hline $\mathrm{KG}(\% \mathrm{SB})$ & 1,75 & 0,021 & 0,287 & 1,10 & 2,78 & 18,64 \\
\hline $\mathrm{W}$ & 2,84 & 0,049 & 0,656 & 1,35 & 5,39 & 23,07 \\
\hline
\end{tabular}

Ort:ortalama, S.H.: standart hata S.S.:standart sapma, Min:minimum, Maks: maksimum VK:varyasyon katsayis1

Çalı̧̧mada incelenen ve vücut ölçümleri alınan $A$. boyeri bireylerinin, türün ayrımında önemli olan metrik uzunlukları ve standart boylarına ait ilişki denklemleri Tablo 3'te gösterilmiştir. Balığın; burunucu- 1. dorsal yüzgeç arası, burunucu- 2. dorsal yüzgeç arası ve preanal mesafelerinin standart boyla olan ilişki katsayılarının kuvvetli olduğu belirlenmiş̧tir.

Tablo 3. Gümüş balığında morfometrik karakterlerin standart boyla olan regresyon denklemleri

\begin{tabular}{lcc}
\hline Morfometrik Karakterler (mm) & Denklemler & $\mathbf{R}^{2}$ \\
\hline Preorbital Mesafe & $0,0591 \mathrm{SB}+0,3891$ & 0,46 \\
Göz Çapı & $0,0477 \mathrm{SB}+2,2292$ & 0,37 \\
Solungaç Kapă̆ı Uzunluğu & $0,0542 \mathrm{SB}+0,9782$ & 0,41 \\
İnterorbital Mesafe & $0,0506 \mathrm{SB}+0,031$ & 0,49 \\
Baş Boyu & $0,1882 \mathrm{SB}+3,1498$ & 0,69 \\
Burunucu 1. Dorsal Y. Arası Mesafe & $0,4279 \mathrm{SB}+0,9831$ & $\mathbf{0 , 8 3}$ \\
Burunucu 2. Dorsal Y. Arası Mesafe & $0,6597 \mathrm{SB}+0,2264$ & $\mathbf{0 , 9 1}$ \\
Preanal Mesafe & $0,6341 \mathrm{SB}+0,3748$ & $\mathbf{0 , 9 2}$ \\
Maksimum Vücut Yüksekliği & $0,1842 \mathrm{SB}-2,9206$ & 0,57 \\
\hline \hline
\end{tabular}


Eğirdir Gölü’nde yaşayan gümüş balığı bireylerinin ortalama tam boyu 79,55 mm ve ortalama ağırlığı 2,84 g olarak ölçülmüş (Tablo 4), boy-ağırlık ilişsisi hesaplanmıştır (Şekil 6). Boy-ağırlık ilişki denklemi W =0,000002L $\mathrm{L}^{3,2549}$ olarak bulunmuştur.

Tablo 4. Gümüş balığının tam boy ve ağırlık dağılımları

\begin{tabular}{lc}
\hline \hline & Ort. \pm S.H. (Min-Maks) \\
\hline Tam Boy (mm) & $79,55 \pm 0,408(58,98-95,00)$ \\
Ăğırlık (g) & $2,84 \pm 0,049(1,35-5,39)$ \\
\hline \hline
\end{tabular}

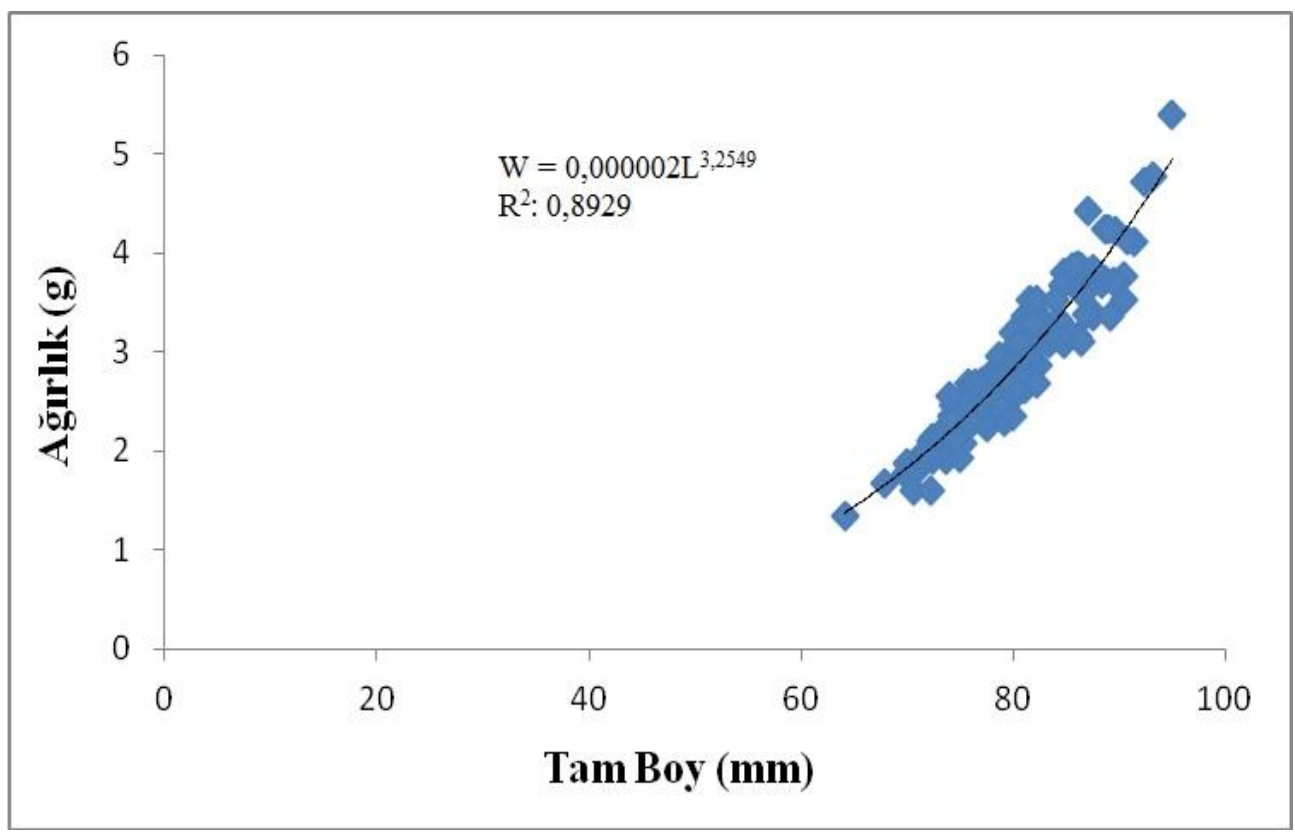

Şekil 6. Gümüş balığı bireyleri için boy-ağırlık ilişkisi grafiği

Türün sistematiğinde kullanılan kemiklerin, seçilen eksenlerdeki ölçümleri değerlendirildiğinde; sol maksil kemiğinin ölçülen iki eksende de sağ maksil kemiğinden daha uzun olduğu belirlenmiştir. Sağ ve sol maksil kemikleri üzerinde belirlenen eksenlerde alınan uzunluklar arasındaki farkların her iki eksende de önemli olduğu bulunmuştur $(\mathrm{P}<0,05)$ (Şekil 2) (Tablo 5).

Tablo 5. Gümüş balığının sağ ve sol maksil kemiklerine ait uzunluk değerleri $(n=135)$

\begin{tabular}{lcccc}
\hline \hline & Sağ maksil-A & Sol maksil-A & Să̆ maksil-B & Sol maksil-B \\
\hline Ort. & 1,7677 & 1,8071 & 6,5111 & 6,6228 \\
S.H. & 0,0159 & 0,0187 & 0,0374 & 0,0384 \\
S.S. & 0,1685 & 0,1977 & 0,3959 & 0,4064 \\
Min. & 1,278 & 1,190 & 5,090 & 5,218 \\
Maks. & 2,121 & 2,265 & 7,273 & 7,413 \\
\hline \hline
\end{tabular}


Sağ ve sol premaksil kemiklerinin dikey ve yatay eksende alınan uzunlukları incelendiğinde, A ekseninin sol premaksilde daha uzun, B ekseninin ise sağ premaksilde daha uzun olduğu göze çarpmaktadır. Sağ ve sol premaksil kemikleri arasındaki bu farklılıklar B ekseni için önemli $(\mathrm{P}<0,05)$, A ekseni için önemsizdir $(\mathrm{P}>0,05)$ (Şekil 3) (Tablo 6).

Tablo 6. Gümüş balığının sağ ve sol premaksil kemiklerine ait uzunluk değerleri $(n=182)$

\begin{tabular}{lcccc}
\hline \hline & Să̆ premaksil-A & Sol premaksil-A & Să̆ premaksil-B & Sol premaksil-B \\
\hline Ort. & 4,4769 & 4,4878 & 6,0125 & 5,9192 \\
S.H. & 0,0267 & 0,0273 & 0,0311 & 0,0341 \\
S.S. & 0,3278 & 0,3349 & 0,3846 & 0,422 \\
Min. & 3,315 & 3,383 & 4,655 & 4,487 \\
Maks. & 5,317 & 5,300 & 6,967 & 6,989 \\
\hline \hline
\end{tabular}

Sağ ve sol operkül üzerinde belirlenen eksenlerde alınan uzunluklar arasında da farklılıklar saptanmıştır. Sol operkül kemiğinin hem A hem de B ekseni uzunluklarının sağ operkülden fazla olduğu ve aralarındaki bu farklılığın önemsiz $(\mathrm{P}>0,05)$ olduğu belirlenmiştir (Şekil 4) (Tablo 7).

Tablo 7. Gümüş balığının sağ ve sol operkül kemiklerine ait uzunluk değerleri (n=134)

\begin{tabular}{lcccc}
\hline \hline & Sağ operkül-A & Sol operkül-A & Să̆ operkül-B & Sol operkül-B \\
\hline Ort. & 6,2012 & 6,2301 & 5,1201 & 5,1608 \\
S.H. & 0,0411 & 0,0394 & 0,0372 & 0,0395 \\
S.S. & 0,4296 & 0,4113 & 0,3831 & 0,4049 \\
Min. & 4,634 & 4,800 & 4,128 & 3,910 \\
Maks. & 7,049 & 7,049 & 6,102 & 6,676 \\
\hline \hline
\end{tabular}

Sağ ve sol preoperkül kemikleri üzerinde alınan dört eksen ölçümüne bakıldığında, A ve B eksenleri için sağ preoperkülün sol preoperkülden daha büyük, $C$ ve $D$ eksenlerinde ise daha küçük olduğu belirlenmiştir. Kemik çiftleri arasındaki bu farklılıkların B ve D eksenleri için önemli $(\mathrm{P}<0,05)$, A ve $\mathrm{C}$ eksenleri için önemsiz $(\mathrm{P}>0,05)$ olduğu bulunmuştur (Şekil 5) (Tablo 8).

Tablo 8. Gümüş balığının sağ ve sol preoperkül kemiklerine ait uzunluk değerleri $(n=182)$

\begin{tabular}{lllllllll}
\hline \hline & $\begin{array}{l}\text { Să } \\
\text { preop-A }\end{array}$ & $\begin{array}{l}\text { Sol } \\
\text { preop-A }\end{array}$ & $\begin{array}{l}\text { Să̆ } \\
\text { preop-B }\end{array}$ & $\begin{array}{l}\text { Sol } \\
\text { preop-B }\end{array}$ & $\begin{array}{l}\text { Sağ } \\
\text { preop-C }\end{array}$ & $\begin{array}{l}\text { Sol } \\
\text { preop-C }\end{array}$ & $\begin{array}{l}\text { Sağ } \\
\text { preop-D }\end{array}$ & $\begin{array}{l}\text { Sol } \\
\text { preop-D }\end{array}$ \\
\hline Ort. & 7,5928 & 7,5740 & 5,5135 & 5,4381 & 5,5025 & 5,5241 & 2,1218 & 2,1555 \\
S.H. & 0,0429 & 0,0422 & 0,0344 & 0,0358 & 0,0376 & 0,0349 & 0,0193 & 0,0192 \\
S.S. & 0,4716 & 0,4646 & 0,3751 & 0,3907 & 0,4123 & 0,3822 & 0,2109 & 0,210 \\
Min. & 5,752 & 5,803 & 4,048 & 4,006 & 4,076 & 4,225 & 1,523 & 1,562 \\
Maks & 8,656 & 8,715 & 6,336 & 6,445 & 6,634 & 6,612 & 2,722 & 2,725 \\
\hline \hline
\end{tabular}




\section{TARTIŞMA VE SONUÇ}

Balık popülasyonları arasındaki değişimleri belirlemede kullanılan morfometrik özellikler önemli belirleyicidirler. Ülkemizde son yıllarda pelajik ve demersal balık türlerinin morfometrik özellikleri belirlenmeye çalışılmaktadır (Turan ve Başusta, 2001; Turan, 2004; Gürkan ve Bayhan, 2009; Kontaş, 2012; Keskin, 2013). Bu çalışmaların çoğunda araştırmacılar balık grupları arasındaki benzerlik ve farklılıkları belirlemek amaciyla morfometrik karakterlerden faydalanmıştır. $\mathrm{Bu}$ çalışmada alınan metrik uzunlukların ortalama, standart sapma, standart hata, minimum, maksimum ve varyasyon katsayısı değerleri hesaplanmıştır. Bulunan değerlere göre, en çok değişken özellik ağırlık iken, en az değişkenlik prepektoral mesafede tespit edilmiştir (Tablo 2). Taşkavak vd., (2012) yaptıkları çalışmalarında; gümüş balığı Atherina boyeri Risso, 1810'nin doğrusal regresyon değerleri arasında tam boyla en yakın ilişkili olan morfometrik karakterleri; II. dorsal yüzgeç-burun ucu arası mesafe $\left(r^{2}=0,94\right)$, anal yüzgeç-burun ucu arası uzaklık $\left(r^{2}=0,91\right)$ ve vücut yüksekliği $\left(r^{2}=0,85\right)$ arasında, en zayıf ilişkili olan morfometrik karakterleri ise gözler arası mesafe $\left(r^{2}=0,53\right)$ ve I. ve II. dorsal yüzgeçler arası mesafe $\left(r^{2}=0,51\right)$ ile I. dorsal yüzgeç boyunda hesaplamışlardır $\left(r^{2}=0,50\right)$.

Eğirdir Gölü $A$. boyeri popülasyonu bireylerinin, türün ayrımında önemli olan metrik uzunlukları ve standart boylarına ait ilişkilerine bakıldığında ise burun ucu 1. dorsal yüzgeç arası $\left(r^{2}=0,83\right)$, burun ucu 2. dorsal yüzgeç arası $\left(r^{2}=0,91\right)$ ve preanal $\left(r^{2}=0,92\right)$ mesafelerinin standart boyla olan ilişki katsayılarının kuvvetli olduğu belirlenmiştir (Tablo 3). Standart boy ile en zayıf ilişkiler ise, göz çap1 $\left(\mathrm{r}^{2}=0,37\right)$ ve solungaç kapağ1 uzunluğunda $\left(\mathrm{r}^{2}=0,41\right)$ tespit edilmiştir. Taşkavak vd. (2012), İzmir Körfezi A.boyeri popülasyonu bireyleri için verilen baş boyu- tam boy ve baş boyu-göz çapı ölçümlerini önceki çalışmalarla karşılaştırmış ve çalışmada elde edilen baş boyu-tam boy $(4,8)$ ile göz çap1-baş boyu $(2,8)$ ortalama değerlerini literatür bulgularına göre büyük olduğunu belirtmişlerdir. Bu çalışmada ise Eğirdir popülasyonu için morfometrik değerlendirmeler sonucunda baş boyu-standart boy ile göz çapı-baş boyu ortalama değerleri sırasıyla 4,3 ve 2,9 olarak hesaplanmıştır. Altun (1999) gümüş balığının morfometrik karakterlerinin deniz, acı su ve tatlı su popülasyonlarında değiştiğini göstermiştir. Morfometrik çalışmalarda genetik olarak ortaya çıkmış yapıların morfo-ekolojik sonuçları ortaya konurken balık popülasyonlarının farklı bölgelerdeki popülasyonlarının morfolojik yapılandırmaları da belirlenmektedir. Morfolojik yapı dışında, boy-ağırlık ve boy-boy ilişkileri de balık stokları ve popülasyonlarının değerlendirilmesinde kullanılan esas parametrelerdir (Ricker, 1968).

A. boyeri için önemli birer taksonomik karakter olan kemikler; Eğirdir popülasyonu incelendiğinde; sağ ve sol maksil üzerinde belirlenen eksenlerde alınan uzunluklar arasındaki farklılıkların her iki eksen için de önemli olduğu $(\mathrm{P}<0,05)$ bulunmuştur (Şekil 2, Tablo 5). Premaksil kemikleri içinse sağ ve sol çiftler arasındaki farklılıklar B ekseni için önemli iken $(\mathrm{P}<0,05)$, A ekseni içinse önemsizdir $(\mathrm{P}>0,05)$ (Şekil 3, Tablo 6). Bu bulgu değerlendirmelerinde premaksilin A ekseni için sağ veya sol kemiğin herhangi birinin seçilebileceğini göstermektedir. Operküllere bakıldığında sağ ve sol çiftler arasındaki bu farklılığın önemsiz $(\mathrm{P}>0,05)$ olduğu belirlenmiştir (Şekil 4, Tablo 7). Operküller her iki eksen için de balığın sağ ve solundan seçilebilir. Preoperkül çiftleri arasındaki farklılıkların $\mathrm{B}$ ve $\mathrm{D}$ eksenleri için önemli $(\mathrm{P}<0,05)$, A ve $\mathrm{C}$ eksenleri için önemsiz $(\mathrm{P}>0,05)$ olduğu bulunmuştur (Şekil 5, Tablo 8). Türle ilgili olarak yapılacak çalışmalarda preoperkül kullanılması durumunda morfometrisi alınacak eksenin 
belirlenerek, çalışılacak eksene göre sağ ya da sol oluşu dikkate alınarak çalışılmalıdır. Avşar (1998)'ın bildirdiğine göre, morfometrik, yani ölçülebilen karakterlerde oluşan değişimler fenotipe yansımaktadır. Dolayısıyla, meristik karakterler balığın daha çok genotipik özelliklerini yansitırken, morfometrik karakterler fenotipik özelliklerini yansıtmaktadır. Balıklarda morfolojik ve morfomeristik karakterlerin oluşmasında normal çevresel faktörlerin etkisi kadar anormal çevresel faktörlerin de etkileri vardır. $\mathrm{Bu}$ nedenle, meristik ve morfometrik karakterler stokların ayrılmasında kullanılmaktadır.

Ayrıca gümüş balığının Eğirdir Gölü için belirlenen morfometrik değerlerine ilave olarak taksonomik öneme sahip kemiksi yapılarının biyometrik incelemeleri de yapılarak, sonraki çalışmalarda bu türün farklı lokalitelerdeki popülasyonları ile karşılaştırma imkanı doğmuştur.

\section{KAYNAKLAR}

Altun, Ö. 1999. Gümüş Balığı (Atherina boyeri Risso, 1810) Populasyonlarında Gözlenen Morfolojik Varyasyonlar. Tr. J. Zool., 23(3): 911-918.

Avşar, D. 1998. Balıkçılık Biyolojisi ve Popülasyon Dinamiği. Baki Kitabevi, Adana.

Ekmekçi, F.G. 2013. Türkiye İçsularındaki İstilacı Balıkların Güncel Durumu ve İstilanın Olası Etkileri. Türkiye İstilacı Tatlısu Türleri Çalıştayı: Ulusal Eylem Planı, 12-14 Haziran 2013, İstanbul.

Geldiay, R., Balık, S. 2009. Türkiye Tatlısu Balıkları (Ders Kitabı). Ege Üniversitesi Fen Fakültesi Kitaplar Serisi, No:37, İzmir.

Gürkan, Ş., Bayhan, B. 2009. İzmir Körfezi (Ege Denizi)'ndeki Kancaağız Pisi Balığı Citharus linguatula (Linnaeus, 1758)'nın Bazı Morfometrik Özellikleri. TUBAV Bilim Dergisi (Türkiye Bilimler Akademisi Vakfi), 2(4): 394-398.

İlhan, A., Sarı, H.M. 2013. Marmara Gölü Balık Faunası ve Balıkçılık Faaliyetleri. Ege J. Fish Aqua. Sci., 30(4): 187-191.

Keskin, G. 2013. Aşağı Melet Irmağı'nda (Ordu) Yaşayan Capoeta banarescui'nun Yaş, Büyüme ve Otolit Özellikleri. Yüksek Lisans Tezi, Ordu Üniversitesi, Ordu.

Kontaş, S. 2012. Aşağı Melet Irmağı'nda (Ordu) Yaşayan Bıyıklı Balık (Barbus tauricus Kessler, 1877)'ın Yaş, Büyüme ve Otolit Biyometrisinin Belirlenmesi. Yüksek Lisans Tezi, Ordu Üniversitesi, Ordu.

Kuru, M., Balık, S., Ustaoğlu, M.R., Ünlü, E., Taşkavak, E., Gül, A.,Yılmaz, M., Sarı, H.M., Küçük, F., Kutrup, B., Hamalosmanoğlu, M. 2001. Türkiye'de Bulunan Sulak Alanların Ramsar Sözleşmesi Balık Kriterlerine Göre Değerlendirilme Raporu. T.C. Çevre Bakanlığı, Vakfi Yayını, Ankara.

Küçük, F., Gülle, İ., Güçlü, S.S., Gümüş, E., Demir, O. 2006. Eğirdir Gölü’ne Sonradan Giren Gümüş Balığı (Atherina boyeri, Risso, 1810)'nın Göl Ekosistemine ve Balıkçılığa Etkisi. I. Ulusal Balıklandırma ve Rezervuar Yönetimi Sempozyumu, 7-9 Şubat 2006, Antalya.

Özeren, C.S. 2004. İznik Gölü Balıklarının Taksonomisi ve C.carpio L., 1758 (Sazan), Rutilus frissi Nordmann,1840 (Akbalık) ve Atherina boyeri Risso,1810 (Gümüş balığı)'nin BiyoEkolojik Yönden İncelenmesi. Doktora Tezi, Hacettepe Üniversitesi, Ankara.

Polat, N., Uğurlu, S. 2007. Samsun İli Tatlı Su Balık Faunası. Ladik Doğayı ve Çevreyi Koruma Derneği, Samsun.

Ricker, W.E. 1968. Methods for Assessment of Fish Production in Freshwaters. Blackwell Scientific Publications, Oxford.

Ricker, W.A. 1975. Computation and Interpretation of Biological Statistics of Fish Populations. Bull. Fish. Res. Board Can., 191: 1-382.

Taşkavak, E., Gürkan Ş., Bayhan B. 2012. İzmir Körfezi (Ege Denizi)'nde Gümüş Balığı Atherina boyeri Risso, 1810'nın Biyometrik Özellikleri. Journal of FisheriesSciences.com, 6(1): 1825. 
Turan, C., Başusta, N. 2001. Comparison of Morphometric Characters of Twaite Shad (Alosa fallax nilotica, Geoffroy Saint-Hi-laire, 1808) Among Three Areas in Turkish Seas. Bull. Fr. Peche Piscic., 362/363: 1027-1035.

Turan, C. 2004. Stock Identification of Mediterranean Horse Mackerel (Trachurus mediterraneus) using Morphometric and Meristic Characters. ICES J. Mar. Sci., 61: 774-781.

Yeğen, V., Balık, S., Bostan, H.R., Uysal, Ustaoğlu, R., Sarı, H.M., İlhan, A. 2005. Isparta İli Balık Faunası. T.C. Tarım ve Köy İşleri Bakanlığı Tarımsal Araştırmalar Genel Müdürlüğü Eğirdir Su Ürünleri Araştırma Enstitüsü Müdürlüğü, Yayın No: 4, Eğirdir. 